\title{
The Effectiveness of the Regulatory Regime for Black Carbon Mitigation in the Arctic
}

\author{
Daria Shapovalova ${ }^{\star}$, \\ University of Aberdeen, School of Law, Aberdeen, UK
}

\begin{abstract}
$^{1}$
In addition to being a hazardous air pollutant, Black Carbon is the second-largest contributor to Arctic warming. Its mitigation is being addressed at the international regulatory level by the Arctic Council and the Convention on Long-Range Transboundary Air Pollution (CLRTAP). Whilst the Convention and its protocols are binding documents, the Black Carbon regulation under their framework appears to have 'soft law' characteristics. At the same time, the voluntary Black Carbon and Methane Framework, adopted by the Arctic Council, demonstrates positive compliance and follow-up dynamics compared to earlier norm-creating attempts. This paper argues that the nature of the norm (binding or non-binding) is not the decisive factor regarding effective implementation in the Arctic region. Current efforts to mitigate Black Carbon by means of a non-binding Arctic Council Black Carbon and Methane Framework represent an improvement in the Council's normative function and may have more effect on the behaviour of Arctic States than relevant provisions under the Gothenburg Protocol to the CLRTAP. To support this argument, the first section presents an overview of the Arctic Council as an actor in Arctic policy-making. It then provides an assessment of current efforts to combat Black Carbon carried out by the Arctic Council and the CLRTAP.
\end{abstract}

\section{Keywords: Black Carbon; Arctic Council; CLRTAP; Air Pollution; Climate Change}

Responsible Editor: Tore Henriksen, Professor, Director K.G. Jebsen Centre for the Law of the Sea, Faculty of Law, University of Tromsø - The Arctic University of Norway.

Received: March 2016; Accepted: September 2016; Published: November 2016

Black Carbon (or soot), the second-largest contributor to Arctic warming, ${ }^{2}$ has been on the agenda of climate activists and international institutions for several years now. ${ }^{3}$ However, it was not until 2015 that the Arctic Council adopted a framework to reduce emissions of this particulate matter. ${ }^{4}$ As the Arctic is warming twice as fast as the rest of the world, ${ }^{5}$ approaching the tipping point in a not so distant future, ${ }^{6}$ the necessity to take steps to lower the warming level has become urgent. Black Carbon (BC) is a shortlived climate forcer, meaning it only remains in the atmosphere for a few days or weeks.

${ }^{\star}$ Correspondence to: Daria Shapovalova, School of Law, Taylor Building, University of Aberdeen, AB24 3UB, UK. Email: daria.shapovalova@abdn.ac.uk 
Therefore, while efforts to reduce BC cannot replace long-term efforts to mitigate $\mathrm{CO}_{2}$ emissions, ${ }^{7}$ immediate reductions in $\mathrm{BC}$ emissions could lower the rate of Arctic warming over the next few decades. ${ }^{8}$ In addition to its warming effects, BC has negative effects on human health causing respiratory diseases that sometimes lead to premature deaths. ${ }^{9}$

The present paper examines whether the current efforts of BC mitigation by means of the Arctic Council's non-binding Framework demonstrate an improvement in the Council's normative function and may have more effect on the behaviour of the Arctic States than the relevant obligations under the legally binding Gothenburg Protocol to the Convention on Long-Range Transboundary Air Pollution (CLRTAP). To this end, the first section introduces BC as an Arctic pollutant. The paper goes on to analyse BC regulation under CLRTAP. Then it presents an overview of the Arctic Council as an actor in Arctic policy-making. The fourth section examines the Arctic Council's work on regulating BC. Finally, the fifth section evaluates national implementation of this regulation.

\section{BC as an Arctic Pollutant}

BC, a particulate matter 'formed through the incomplete combustion of fossil fuels, biofuel, and biomass, ${ }^{10}$ warms the atmosphere by absorbing sunlight. In the Arctic, the effects of BC are especially noticeable since it darkens snow and ice thus reducing the albedo (ability to reflect sunlight) effect. ${ }^{11}$ Melting snow and ice expose dark ocean or land that has a much lower albedo and absorbs even more sunlight thus creating a positive feedback loop.

In the Arctic, BC sources include open burning, and the use of diesel for vehicles and electricity generation. ${ }^{12}$ Until recently, the oil and gas sector was not believed to be responsible for significant BC emissions in the High North. ${ }^{13}$ However, recent studies reveal that this sector's share of hydrocarbons emissions has been underestimated. ${ }^{14}$ It is estimated that around $42 \%$ of BC in the Arctic arises from associated petroleum gas (APG) flaring during oil and gas production in the region. ${ }^{15}$ Whereas $\mathrm{BC}$ emissions from shipping have not yet been identified as a primary source, they are expected to increase with a high-growth scenario for Arctic shipping 'nearly fivefold by 2030 and over 18-fold by $2050 .{ }^{16}$ A recent open letter from 15 environmental NGOs to the Chair of the Senior Arctic Officials group calls for a ban on heavy fuel oil, a primary source of BC emissions from ships. ${ }^{17}$

The distinct nature of the $\mathrm{BC}$ problem is that it is both an air pollutant and a contributor to climate change. Air quality is one of the major branches of international environmental law, starting with the Trail Smelter arbitration in 1939. ${ }^{18}$ On the international level, BC, as an air pollutant, is covered by Gothenburg Protocol to the CLRTAP. As a climate forcer, it is addressed by the non-binding framework of the Arctic Council. This 'dual' nature makes it possible to reduce BC's warming effects while also reducing population health risks. The Council, a high-level intergovernmental forum of Arctic States, recognises the challenges presented by climate change and is working on its mitigation through joint assessment and non-binding legislation. ${ }^{19}$ The Arctic States chair the Council in two-year rotations, with each 


\section{Shapovalova}

chair State focusing on certain topics. The US, as the new chair State, has chosen to address the impacts of climate change as one of three focus areas for 2015-2017 and has emphasised the necessity of addressing the BC issue. ${ }^{20}$

The CLRTAP is 'the only major regional multilateral agreement devoted to the regulation and control of transboundary air pollution. ${ }^{21}$ The Convention was adopted under the auspices of the UN Economic Commission for Europe (UNECE). Despite its European focus, Canada and the US are members of UNECE and CLRTAP signatories. This is particularly relevant since Canada and the US are both Arctic States and large BC emitters. The Gothenburg Protocol to the CLRTAP, which defines quantitative reduction targets, was amended in 2012 to include $\mathrm{PM}_{2.5}$, or particulate matter less than 2.5 micrometres in diameter, of which BC is a component. $^{22}$

\section{Convention on Long-Range Transboundary Air Pollution and BC}

BC has been on the research and political agenda internationally for several years. ${ }^{23}$ In 2009, the Executive Body of the CLRTAP ${ }^{24}$ established an Ad Hoc Expert Group on Black Carbon, ${ }^{25}$ with particular reference to the unique role BC plays in snow and ice-covered areas, such as the Arctic. The CLRTAP is in principle different from the Arctic Council: it is not primarily concerned, nor was it designed to be, with the Arctic environment specifically. ${ }^{26}$ It is an international, legally binding agreement, a source of international law as defined by the International Court of Justice Statute. ${ }^{27}$ It was first adopted in response to European acid rain problems, but has since expanded its influence to many other air pollution issues through the adoption of additional protocols. Nevertheless, it is worth analysing the CLRTAP in the context of BC pollution to demonstrate any potential interaction and/ or differences in effects between this targeted regional, but non-binding approach, and a broader binding international legal instrument.

In 2012, upon the recommendations of the Expert Group, the Gothenburg Protocol to the CLRTAP ${ }^{28}$ was updated to include $\mathrm{PM}_{2.5}$, or 'particulate matter' of which BC is a component. ${ }^{29}$ It is important to stress, at this point, that whilst the Gothenburg Protocol is a legally binding instrument, its BC provisions are voluntary. The voluntary nature of the provisions is reiterated by using specific wording, such as 'should' and 'as [a State] considers appropriate.',

However, whilst all the Arctic States are Parties to the CLRTAP, Canada, Russia and Iceland have not yet ratified the Protocol. Even for State Parties, the Protocol provides flexible mechanisms with regards to amendments. Amendments to the Protocol are approved by consensus, which 'politicizes a decision that ought to be based on objective scientific criteria and the precautionary principle. ${ }^{31}$ Moreover, even after adoption, the amendment to Annex II (Reduction Commitments) does not enter into force immediately. It only does so for Parties that have explicitly accepted the amendment 90 days after two thirds of Parties at the time of adoption expressed their acceptance. ${ }^{32}$ This mechanism has allowed the US to set an 
indicative target for $\mathrm{PM}_{2.5}$ reduction, ${ }^{33}$ rather than accepting any binding reduction targets. Thus, out of eight Arctic States, only the four Nordic countries have agreed to $\mathrm{PM}_{2.5}$ reduction goals. With Canada, Russia and the US out of the picture, the biggest polluters in the Arctic are either left outside the jurisdiction of the Protocol or do not have binding reduction obligations under it.

The questions remain: Should all of the Arctic States ratify the Gothenburg Protocol and/or its 2012 amendment? If so, would this be an effective solution to the Arctic BC problem?

The CLRTAP proved itself effective in dealing with acid rain, the problem that prompted its creation. ${ }^{34}$ However, it is argued that improvements came from 'domestic factors largely unrelated to the CLRTAP.' ${ }^{35}$ Compliance with the Protocol is reviewed by the Implementation Committee of the CLRTAP, ${ }^{36}$ which meets twice a year to review reports submitted by State Parties. ${ }^{37}$ Should the Committee not be satisfied with compliance, it then prepares a report for the Executive Body, which can then issue a compliance note urging a Party to 'fulfil its obligations as soon as possible. ${ }^{38}$ No other compliance mechanism is provided for in the Protocol. Moreover, reporting on BC is explicitly voluntary under the Protocol. ${ }^{39}$

Thus, despite the Gothenburg Protocol being a binding international instrument, it is fair to argue that the regulation of BC under its framework is more characteristic of soft law. ${ }^{40}$ That being said, it is not clear whether the 2012 amendments to the Protocol will actually create changes in the national legislation of the Arctic States that will help reduce BC emissions. The four Nordic Arctic States were the only States to undertake quantitative $\mathrm{PM}_{2.5}$ reduction goals. They have agreed to reduce their emissions by around 30\% compared to 2005 levels. ${ }^{41}$ However, work to reduce SLCFs and PM had begun in these States prior to these commitments. ${ }^{42}$ In fact, it was Norway that proposed the amendments to the Protocol in the first place. ${ }^{43}$ Thus, while at this point, the CLRTAP might not be the most effective instrument to combat BC in the Arctic, it is an important venue for further scientific work and abatement strategies. With further insights on Arctic BC research from the Arctic Council's Arctic Monitoring and Assessment Programme (AMAP), it could have more potential for effectiveness in the future.

\section{Arctic Council as an Influencer in Environmental Policy-Making}

Growing awareness of the Arctic as a unique region of the world has led to the emergence of distinct Arctic regimes in international law. ${ }^{44}$ The Arctic environmental legal regime consists of the relevant national legislation of the Arctic States, international binding agreements and soft law documents, customary law, and the frameworks developed by the Arctic Council.

Environmental protection of the Arctic was the driving factor that first brought the Arctic States together to establish the Arctic Environmental Protection Strategy (AEPS) in 1991. Prior to the AEPS, there had been occasional cases of cooperation on environmental matters between the Arctic States, such as the 1973 Polar Bear Conservation Agreement ${ }^{45}$ and 1911 Fur Seals Agreement. ${ }^{46}$ AEPS later 


\section{Shapovalova}

transformed into the Arctic Council, which was established in $1996^{47}$ as a highlevel intergovernmental forum of the Arctic States. ${ }^{48}$ The Arctic Council is usually described as a 'soft law regime'49 as it does not have the power to make binding decisions. Although academics and commentators regularly call for a 'binding Arctic treaty' to be adopted to ensure environmental protection of the region; ${ }^{50}$ the Council has been working for 20 years both as a knowledge institution and a policy influencer.

The effectiveness of the Council as an institution and an Arctic regime-maker has been the focus of several studies in recent years. ${ }^{51}$ In 2007, Geir Hønnelannd and Olav Stokke of the Fridtjof Nansen Institute published a study that concludes that the Council is most effective in areas where it 'enjoys niche advantages' 52 such as environmental monitoring, encouraging the Arctic States to take a common stand on hazardous pollutants and 'capacity enhancement in certain areas. ${ }^{53}$ However, when it comes to its normative contribution, the authors conclude that the Council's capacities are 'limited'. 54

Since this publication, the Arctic Council has become more active as a norm creator and influencer. It has hosted the adoption of two binding treaties, ${ }^{55}$ updated its voluntary guidelines ${ }^{56}$ and concluded a new framework agreement. ${ }^{57}$ The normative function of the Council, however, is still viewed by some as something that should be left to the complex governance framework surrounding the region, focusing instead on conducting 'large-scale scientific assessments' that assist policy-shaping. ${ }^{58}$

Indeed, the Council, as a knowledge institution, successfully provides policymakers with valuable scientific data from the Arctic. ${ }^{59}$ Serving as a mediator between science and policy-makers, the Council assisted with 'raising the visibility' ${ }^{60}$ of certain problematic issues on the Arctic policy agenda, of which BC is one. In some cases, this has translated into better policies for the region coming from other international fora. In particular, the Council's role in negotiations on the Stockholm Persistent Organic Pollutants (POPs) Convention ${ }^{61}$ and Minamata Mercury Convention ${ }^{62}$ has been emphasized. ${ }^{63}$

The Stockholm POPs Convention was negotiated with the active involvement of those mainly affected by POPs, Arctic indigenous peoples. ${ }^{64}$ It was signed and ratified by seven of the eight Arctic States. ${ }^{65}$ Arctic ecosystems and indigenous communities are specifically mentioned in the preamble of the Convention as 'particularly at risk." 66 In addition, scientific data provided by the AMAP was 'used effectively' in the preparatory process leading up to the Stockholm Convention. The Finnish representative reportedly intervened on behalf of the Arctic Council during the negotiations to promote regional concerns. ${ }^{67}$

Moreover, the Convention contains a provision that requires effectiveness evaluation every four years. ${ }^{68}$ This monitoring activity brings together researchers from regional groups to collect and analyse data on POPs emissions reduction. The $\mathrm{AMAP}^{69}$ conducts these assessments for the Arctic region. Recent data demonstrates a reduction and stabilisation in POPs concentrations across the Arctic region. ${ }^{70}$

The Arctic Council has been an important actor in the POPs regime creation through its scientific, as well as institutional capacity. However, so far the Council's 
climate-related findings have 'had very limited concrete influence on global and national climate law and policy'. ${ }^{71}$ The Council's involvement with BC issues is addressed in the next section.

\section{The Arctic Council and BC}

The Arctic Council first acknowledged short-lived climate forcers (SLCFs) ${ }^{72}$ in 2009 , during a Ministerial Meeting in Tromsø, Norway, by creating a Task Force on SLCFs and charging it with the task 'to identify existing and new measures to reduce emissions of these forcers and recommend further immediate actions that can be taken and to report on progress at the next Ministerial Meeting. ${ }^{73}$ Later in the year, the task was refined to focus on BC due to its 'unique role ${ }^{74}$ in the Arctic. After publishing two reports, ${ }^{75}$ the Task Force was restructured into the Task for Action on BC and Methane (TFABCM). ${ }^{76}$ In 2013, during a Ministerial Meeting in Kiruna, Sweden, the Council recognised that a reduction in BC emissions 'could slow Arctic and global climate change and have positive effects on health" ${ }^{, 7}$ and made national BC emissions inventories 'a matter of priority. ${ }^{78}$ The main normative deliverable produced following the work of the Task Force is the Framework for Enhanced Action to Reduce Black Carbon and Methane Emissions. ${ }^{79}$ It was decided that the document would refrain from setting any quantitative targets until 2017, even though just two months prior to this decision during the fifth meeting of the TFABCM, 'most [participants] indicated a preference for a quantitative vision'. ${ }^{80}$

Instead, the Framework was intended to 'send a strong political signal in the form of an ambitious, politically aspirational collective vision. ${ }^{81}$ The Framework has been received as a 'breakthrough. ${ }^{82}$ The decision not to set a common reduction target can be explained by a number of factors. First, scientific work on BC emissions sources, detection, and analysis is still ongoing. Some large emitters, such as Russia, have not had effectively documented inventories until recently. ${ }^{83}$ Second, setting quantitative targets for the Arctic States alone would not solve the problem, as large quantities of BC come from Western Europe and South East Asia.

It was noted that this document marked 'the first time that Arctic nations have formally agreed to work together to mitigate climate change (...) sending a hugely important political message that climate change mitigation can be organized regionally as well as globally. ${ }^{84}$ Implementation of the Framework will be assessed by the Expert Group once every two years with the first results expected in 2017.

Whilst the document has been initially well-received, it will be behavioural changes at the national level that determine its success. The framework might be a positive starting point in the normative regulation of BC. However, the Arctic Council's non-binding documents lack follow-up mechanisms. ${ }^{85}$ For the BC and Methane Framework to achieve its goals, it requires national follow-up, implementation and reporting.

The first outcomes of the Framework were received in September 2015 when the first round of reports was submitted. The scope of the Framework does not end at 


\section{Shapovalova}

reporting; a compilation of national submissions is reviewed by the Expert Group, which, in turn, issues 'conclusions and specific recommendations' ${ }^{86}$ to guide further action. The Arctic Council thus uses its scientific capacity to evaluate policy actions and effects, which might prove more effective than simply issuing guidelines. To provide more insight into this process, the reports and actions of the Arctic States on $\mathrm{BC}$ emissions at the national level are analysed in the next section.

\section{Effectiveness and National Implementation}

As of March 2016, all of the Arctic Council States, eight Observer States, and the EU had submitted their reports to the Council. These national submissions are not standard emissions data sheets, but rather comprehensive reports containing mitigation measures, Arctic-relevant project descriptions, cross-border cooperation examples, and best practices.

The national submissions under the Arctic Council's Framework are varied and should be analysed in the context of individual BC emissions levels. Thus, for example, Iceland's non-submission of a full BC inventory might be viewed as noncompliance. Yet, when analysed in a broader context, it can be asserted that Iceland's BC emissions are negligible compared to the other Arctic States (see Figure 1 below).

The main takeaways of the national submissions and the subsequent actions taken by the Arctic States are as follows: on the whole, BC emissions across the region are in decline, mostly through national air pollution regulations; the sources of BC vary across the States; the Arctic Council's Framework has facilitated the creation of political momentum that has enhanced BC research and political action; the Arctic BC mitigation action is further reinforced by the availability of the AMAP's monitoring capacity. These assumptions are elaborated below.

In general, BC emissions have been in decline over the past decade. That being said, BC has never been a direct target of legislation. This is where the dual nature of $\mathrm{BC}$ as an air pollutant and a climate forcer comes into play. At the national level, BC has been addressed indirectly, through air pollution control laws, rather than climate change frameworks. Additionally, a number of projects directed at mitigating BC and funded by the Council's Project Support Instrument were implemented in the Russian Arctic. These projects include joint US-Russia initiatives to update the bus

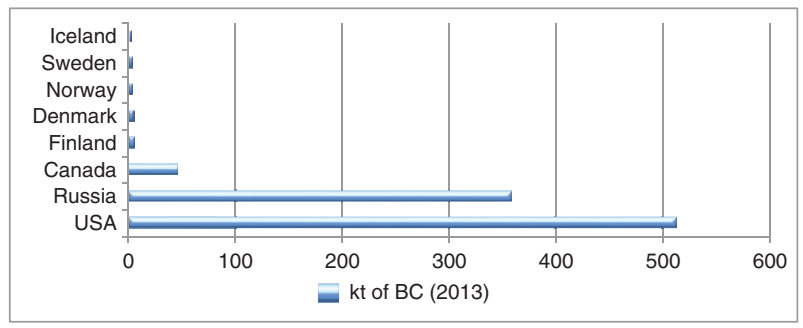

Figure 1. Annual BC emissions in the Arctic States

Data source: national submissions of the Arctic States. 
fleet in the Murmansk area ${ }^{87}$ and energy upgrades to off-grid cluster settlements in Karelia. ${ }^{88}$ Sources of BC vary largely across the Arctic States: in Russia, almost half of $\mathrm{BC}$ emissions comes from flaring and venting. However, prior to targeted $\mathrm{BC}$ assessment in the Russian Arctic, it was believed that the two main sources were 'forest fires and firewood, coal, and liquid fuel combustion by individuals and small boilers. ${ }^{89}$ Thus, the oil and gas industry's contribution to Russian BC emissions has been largely underestimated. Russia flares the second-largest amount of associated petroleum gas in the world (after Nigeria) and would benefit from improving its relevant laws and working closely with the oil and gas sector in their implementation. ${ }^{90}$ The Russian submission states that since a new system of fines for gas flaring came into effect in early 2015, flaring levels have been 'cut in half.' 91

In Canada and the US, most BC pollution originates from mobile sources and diesel-powered transport. The US submission credits its national regulations on new and existing engines with the gradual BC emissions decline, but admits that potential exists for further reduction from residential wood burning as well as oil and gas development activities. In the US National Strategy for the Arctic Region Implementation Framework, implementation of the Arctic Council Framework is mentioned specifically in the broader context of BC reduction. Participation in CLRTAP activities is discussed in the context of involving AMAP and 'other international platforms. ${ }^{92}$ Moreover, the most recent Bureau of Ocean Energy Management has proposed air quality control regulations for oil and gas operations on the outer continental shelf (including Alaska) and specifically mentioned warming effects of BC and concerns over its depositions on snow and ice in Alaska and other parts of the Arctic. ${ }^{93}$ Canada refers to its commitment as a member of the Arctic Council as a prompt to produce annual BC emissions inventories. ${ }^{94}$ These commitments are reiterated in the latest 2016 inventory. ${ }^{95}$ National mitigation measures in Canada are similar to the ones in the US; existing reductions are mainly credited to transportation regulations. Further reduction is anticipated through new standards on air quality for the industry as well as localised projects in remote settlements that rely mostly on diesel fuel for electricity generation.

In the Nordic countries, the primary source of BC emissions is stationary residential. Norway refers to knowledge gathering on mitigation strategies ${ }^{96}$ as well as best practices for reducing emissions from the oil and gas sector. ${ }^{97}$ Sweden and Finland list existing sectoral mitigation regulations as well as ongoing work with the EU as having potential for future reductions. Especially in the Nordic context, the EU Ecodesign Directive regulating residential heating emissions limit values is relevant and mentioned by both submissions.

In addition to the Arctic Council States, eight Observers and the EU also submitted national reports. Whilst not as elaborate as the Arctic States, they do represent a step towards a more inclusive role of Observers in the Council. Given that Asian States account for $43 \%$ of BC burdens in the Arctic, ${ }^{98}$ involving them in this process holds significant potential. However, as Professor Johnstone points out, negotiating a binding treaty with them would take the matter out of the Council's control and be 'more difficult and time-consuming." 


\section{Shapovalova}

The methodology the Council uses for BC reporting has certain advantages. The first advantage is the influence the Council holds over its observers. Emissions from the Arctic States account for only about a third of the warming effects of BC in the region. ${ }^{100}$ Bringing other States into the Framework would potentially stimulate technology transfer and better coordination of national policies, where relevant. While the Gothenburg Protocol has a wider participation number-wise, the Arctic Council's observers include States that contribute greatly to BC concentrations in the Arctic, namely: China, India, Japan, South Korea, India, and Singapore. ${ }^{101}$ The second advantage is that the Arctic Council coordinates reporting with another international instrument that deals with BC - the Gothenburg Protocol to the CLRTAP. ${ }^{102}$ For some States, the reporting requirements of the BC and Methane Framework overlap with the requirements of the CLRTAP. The Framework allows these States to send the Council the 'same submission they sent to the CLRTAP', or more simply, the information regarding 'where it can be collected on the CLRTAP public website. ${ }^{103}$ Simply referencing or providing a link to the CLRTAP data in the emissions level chapters of the national submissions avoids double-reporting and takes the burden off the national institutions responsible for compiling and sending the data. ${ }^{104}$ Since the work on BC in the Arctic Council began in 2009 and its inclusion in the CLRTAP only occurred in 2012, it is not clear what triggered the initial inventory collection by the Arctic States. However, the Canadian 2016 inventory suggests that 'Environment Ministers from Arctic States had previously agreed that the inventories [produced under the Arctic Council Framework] could be voluntarily submitted under the CLRTAP.,105

Additionally, certain States note that the data collection methodology is still under development. The non-binding nature of the Arctic Council Framework allows the document to be flexible and adjustable in the future, should science provide a clearer picture.

Overall, the BC and Methane Framework has had a greater influence on States in the short-term than earlier voluntary documents from the Council. ${ }^{106}$ It is, however, worth noting that some of the States started working on the BC issue prior to signing the Framework ${ }^{107}$ and some of their mitigation strategies might result from obligations under separate commitments (such as compliance with EU legislation and the CLRTAP Gothenburg Protocol). ${ }^{108}$ It is, therefore, problematic to establish the causal links between the Framework and implemented mitigation strategies or to assess fully its effectiveness at this stage.

\section{Conclusions}

In the presence of many overlapping treaties and regimes in the Arctic, it can be argued that the focus should be on the implementation of existing obligations rather than creating new overarching treaties. ${ }^{109}$ However, the presence of two separate legal documents that cover the issue of BC emissions should not be viewed negatively, especially since there is ongoing coordination between the two. ${ }^{110}$ In addition to the utilisation of reporting under the CLRTAP for the purposes of the 
Arctic Council Framework, there are coordination meetings conducted between the Arctic Monitoring and Assessment Programme and the CLRTAP. Currently, the voluntary BC reports under CLRTAP primarily contain emissions data, while the Arctic Council Framework also gathers information on national mitigation strategies and examples of international cooperation, as well as on relevant projects and best practices.

A comparison of the two parallel normative efforts to combat BC is important in two respects. First, the correlation between the formal affiliation of a normative instrument within the realm of 'hard' or 'soft' law and its effectiveness might be overrated. In the present case, States are still reluctant to undertake binding emissions reduction obligations despite the fact that $\mathrm{BC}$ emissions are in steady decline due to existing national policies. BC provisions in the legally binding Gothenburg Protocol have soft law characteristics and do not create concrete obligations for most of the Arctic States.

A flexible framework tailored in accordance with an improved understanding of BC sources and effects is needed at this stage. Such flexibility is likely to best provided by the Arctic Council Framework due to its ability to rapidly change the focus of its work in accordance with priorities. Moreover, the Council's Framework is supported by substantial scientific assessment work, funding for demonstration projects, and a sharing of best practices between the Arctic States as well as Observers through the Arctic Council. Additionally, an analysis of the first round of submissions under the Arctic Council framework reveals that there is no 'one-sizefits-all' solution for reducing Arctic BC. The primary source of BC differs across the region: while Russia would benefit from further improving its flaring legislation, for the Nordic countries it would be more advantageous to focus on a reduction of emissions from wood burning. ${ }^{111}$ The ongoing targets in the Council regarding BC may have helped to place BC issues high on the national political agendas of the Arctic States, and may also have initiated the collection of emission inventories.

Finally, The Arctic Council is growing as a policy-influencer and a 'knowledge institution' as argued by eminent scholars Koivurova, Kankaanpää, and Stępien. ${ }^{112}$ The BC and Methane Framework represents an improvement on earlier soft law instruments that were criticised for a lack of follow-up. The dominant position of BC on the agenda of the previous Canadian as well as current US Chairmanship at the Arctic Council appears to be yielding its first results.

\section{NOTES}

1. Some ideas and concepts from this article originated in the author's previously published chapter: 'The Effectiveness of Current Regulatory Models of Gas Flaring in Light of Black Carbon Emissions Reduction in the Arctic', in Global Challenges in the Arctic Region: Sovereignty, Environment and Geopolitical Balance, ed. Elena Conde and Sarah I Sánchez (Abingdon/New York: Routledge, 2017).

2. After $\mathrm{CO}_{2}$. T. C. Bond et al., 'Bounding the Role of Black Carbon in the Climate System: A Scientific Assessment: Black Carbon in the Climate System', Fournal of Geophysical Research: Atmospheres 118, no. 11 (16 June 2013): 5380-5552, doi: 10.1002/jgrd.50171. 


\section{Shapovalova}

3. Executive Body of the Convention on Long-Range Transboundary Air Pollution, Decision 2009/5 Establishment of an Ad Hoc Expert Group on Black Carbon ECE/EB.AIR/99/ ADD.1; UNEP and WMO, 'Integrated Assessment of Black Carbon and Tropospheric Ozone', 2011; Arctic Council Task Force on Short-Lived Climate Forcers, 'Progress Report and Recommendation for Ministers', 2011.

4. Arctic Council, Enhanced Black Carbon and Methane Emissions Reductions: An Arctic Council Framework for Action, Annex 4 to the SAO Report to the Ministers, Iqaluit Ministerial Meeting, 24 April 2015 (Arctic Council BC and Methane Framework for Action).

5. National Oceanic and Atmospheric Administration, 'Arctic Report Card', 2014, accessed March 28, 2016, http://www.arctic.noaa.gov/reportcard/.

6. Timothy M Lenton et al., 'Tipping Elements in the Earth's Climate System', PNAS 105, no. 6 (2008): 1789.

7. The World Bank and International Cryosphere Climate Initiative, 'On Thin Ice: How Cutting Pollution Can Slow Warming and Save Lives', 2013, xvii, accessed March 28, 2016, https://www.wdronline.worldbank.org/handle/10986/16628.

8. T. C. Bond et al., 'Bounding the Role of Black Carbon in the Climate System: A Scientific Assessment: Black Carbon in the Climate System,' fournal of Geophysical Research: Atmospheres 118, no. 11 (June 16, 2013): 5380-5552, doi: 10.1002/jgrd.50171; Arctic Council Task Force on Short-Lived Climate Forcers, 'Recommendations to Reduce Black Carbon and Methane Emissions to Slow Arctic Climate Change,'2013, 2; The World Bank and International Cryosphere Climate Initiative, 'On Thin Ice', 2.

9. United Nations Environmental Programme and World Meteorological Organisation, Integrated Assessment of Black Carbon and Tropospheric Ozone (2011) 96.

10. US Environmental Protection Agency, 'Black Carbon and Its Effects on Climate,' in Report to Congress on Black Carbon, 2012.

11. UNEP and WMO, 'Integrated Assessment of Black Carbon and Tropospheric Ozone,' 276.

12. Arctic Council Task Force on Short-Lived Climate Forcers, 'Recommendations to Reduce Black Carbon and Methane Emissions to Slow Arctic Climate Change,' 6.

13. Ibid.

14. The World Bank and International Cryosphere Climate Initiative, 'On Thin Ice,' 57; A. Stohl et al., 'Black Carbon in the Arctic: The Underestimated Role of Gas Flaring and Residential Combustion Emissions', Atmospheric Chemistry and Physics 13, no. 17 (September 5, 2013): 8833-8855, doi: 10.5194/acp-13-8833-2013.

15. Stohl et al., 'Black Carbon in the Arctic.'.

16. '15 NGOs Petition Arctic Council on HFO,' Maritime Executive, January 29, 2016, accessed March 28, 2016, http://www.maritime-executive.com/article/fifteen-ngos-petitionarctic-council-on-hfo.

17. Accessed March 28, 2016, http://arcticjournal.com/sites/default/files/letter_from_ngos_to_ amb._balton_re_hfo_use_and_arctic_shipping_-_26_jan_2016.pdf.

18. Trail Smelter Arbitration (US v Canada) AfIL 33 (1939): 182.

19. Arctic Council, Protection of the Arctic Marine Environment (PAME), Arctic Offshore Oil and Gas Guidelines (adopted April 29, 2009) s 6.3; Arctic Council Secretariat, Kiruna Declaration of the $8^{\text {th }}$ Ministerial Meeting of the Arctic Council (May 15, 2013). On the climate action of the Arctic Council see Timo Koivurova and Md Waliul Hasanat, 'The Climate Policy of the Arctic Council,' in Climate Governance in the Arctic, ed. Timo Koivurova, E. Carina H. Keskitalo, and Nigel Bankes (Dordrecht: Springer, 2009), 51-76.

20. Arctic Council, About the US Chairmanship, accessed March 28, 2016, http://www.arcticcouncil.org/images/attachments/US_Chairmanship/Chairmanship_Brochure_2_page_public. pdf. 
21. Patricia W Birnie and Alan E Boyle, International Law and the Environment, 2nd ed. (Oxford: Oxford University Press, 2002), 506.

22. Executive Body of the CLRTAP, Decision 2012/2 Amendment of the Text of and Annexes II to IX to the 1999 Protocol to Abate Acidification, Eutrophication and Ground-Level Ozone and the Addition of New Annexes X and XI ECE/EB.AIR/111/Add.1.

23. For further discussions on international cooperation efforts for research on BC effects and reduction recommendations see The World Bank and International Cryosphere Climate Initiative, 'On Thin Ice,' 212; Lindsey Griffith, 'The Last Climate Frontier: Leveraging the Arctic Council to Make Progress on Black Carbon and Methane. Policy Prescriptions for Making the U.S. Chairmanship of the Arctic Council Count on Key Climate Variables' (Clean Air Task Force, 2014), 6, 10-11.

24. Convention on Long-Range Transboundary Air Pollution (signed November 3, 1979, entered into force March 16, 1983) UNTS 1302: 217 (CLRTAP).

25. Executive Body of the CLRTAP, Decision 2009/5 Establishment of an Ad Hoc Expert Group on Black Carbon ECE/EB.AIR/99/ADD.1.

26. Nevertheless, the significant effects BC has in the region have been stressed in the Ad Hoc Expert Group on Black Carbon report (Executive Body, $28^{\text {th }}$ session, 2010).

27. Statute of the International Court of Justice (signed June 26, 1945, entered into force October 24, 1945) TS 993, art 38(1).

28. Protocol to the 1979 Convention on Long-Range Transboundary Air Pollution to Abate Acidification, Eutrophication and Ground-Level Ozone (signed November 30, 1999, entered into force May 17, 2005) UNTS 2319: 81 (Gothenburg Protocol).

29. Executive Body of the CLRTAP, Decision 2012/2 Amendment of the Text of and Annexes II to IX to the 1999 Protocol to Abate Acidification, Eutrophication and Ground-Level Ozone and the Addition of New Annexes X and XI ECE/EB.AIR/111/Add.1.

30. Gothenburg Protocol art 3(6).

31. Claudia Saladin, 'The LRTAP POPs Protocol and Its Relevance to the Global POPs Negotiations,' (Center for International Environmental Law, n.d.), 7.

32. Gothenburg Protocol art 13bis (3).

33. ibid Annex II.

34. Marc A Levy, 'European Acid Rain: The Power of Tote-Board Diplomacy,' in Institutions for the Earth: Sources of Effective International Environmental Protection, ed. Robert O Keohane, Marc A Levy, and Peter M Haas (Cambridge: MIT Press, 1993), 127-128; Don Munton et al., 'Acid Rain in Europe and North America,' in The Effectiveness of International Environmental Regimes: Causal Connections and Behavioral Mechanisms, ed. Oran R Young (Cambridge: MIT Press, 1999), 233-234.

35. Cass points out that national transition from coal to natural gas was largely responsible for emissions reduction- Loren R Cass, 'Acid Pollution and Acid Rain', in Routledge Handbook of Global Environmental Politics, ed. Paul G Harris (Abingdon/New York: Routledge, 2014), 395.

36. Was established in 1997 and restructured in 2006 (Executive Body of the CLRTAP, Decision 2006/2 Implementation Committee, its Structure and Functions and Procedures for Review ECE/EB.AIR/2006/2).

37. Ibid 2 and 3(1). Reporting is required by Gothenburg Protocol art 7.

38. See eg, Executive Body of the CLRTAP, Decision 2013/14 Concerning Compliance by the European Union with the Protocol to Abate Acidification, Eutrophication and Groundlevel Ozone (ref. 5/13 (NOx)) ECE/EB.AIR/122/Add.1.

39. Art 7.1 (d)

40. For instances where treaties have characteristics of soft law see Alan E Boyle and Christine M Chinkin, The Making of International Law (Oxford: Oxford University Press, 2007), 220.

41. Gothenburg Protocol Annex II. 


\section{Shapovalova}

42. See eg, Hans Skotte Møller, Nordic Workshop on Action Related to Short-Lived Climate Forcers (Nordic Council of Ministers, 2013).

43. Executive Body of the CLRTAP, Report on the $29^{\text {th }}$ Session (12-16 December 2011) ECE/EB.AIR/109/Corr.1.

44. In particular, there is literature that examines the regime for the Arctic as a whole (see Erika Lennon, 'A Tale of Two Poles: A Comparative Look at the Legal Regimes in the Arctic and the Antarctic', Sustainable Development Law \& Policy 8 (2007): 32.) as well as specific regimes such as Arctic Ocean regime (Christopher C Joyner, 'The Legal Regime for the Arctic Ocean', fournal of Transnational Law E Policy 18 (2008): 195.) or Arctic shipping regime (Sara J. Dresser, 'Safeguarding the Arctic from Accidental Oil Pollution: The Need for a Binding, Region-Specific Shipping Regime', Southwest fournal of International Law 16 (2010): 507.)

45. Agreement on Conservation of Polar Bears (signed November 15, 1973, entered into force May 26,1976) UST 27: 3918.

46. For an overview of earlier measures taken see Donald R Rothwell, 'International Law and the Protection of the Arctic Environment', International \& Comparative Law Quarterly 44, no. 2 (1995): 280-312.

47. Declaration on the Establishment of the Arctic Council (signed September 19, 1996) (Ottawa Declaration).

48. Canada, Denmark, Finland, Iceland, Norway, the Russian Federation, Sweden and the United States of America.

49. Donald R Rothwell, 'Polar Opposites: Environmental Discourses and Management in Antarctica and the Arctic', in Environmental Discourses in Public and International Law, ed. Brad Jessup and Kim Rubenstein (Cambridge: Cambridge University Press, 2012), 367.

50. Kristin Noelle Casper, 'Oil and Gas Development in the Arctic: Softening of Ice Demands Hardening of International Law', Nat Resources $\mathcal{F} 49$ (2009): 825; Melissa A. Verhaag, 'It Is Not Too Late: The Need for a Comprehensive International Treaty to Protect the Arctic Environment', Geo Intl Envtl L Rev 15 (2002): 555.

51. See e.g. Geir Hønneland and Olav Schram Stokke, eds., International Cooperation and Arctic Governance: Regime Effectiveness and Northern Region Building (Abingdon/New York: Routledge, 2007); Paula Kankaanpää and Oran R Young, 'The Effectiveness of the Arctic Council', Polar Research 31 (2012), accessed March 28, 2016, http://dx.doi.org/10.3402/ polar.v31i0.17176; Timo Koivurova, Paula Kankaanpää, and Adam Stępień, 'Innovative Environmental Protection: Lessons from the Arctic', fournal of Environmental Law 27, no. 2 (2015): 285-311.

52. Olav Schram Stokke, 'International Institutions and Arctic Governance', in International Cooperation and Arctic Governance: Regime Effectiveness and Northern Region Building, ed. Geir Hønneland and Olav Schram Stokke (Abingdon/New York: Routledge, 2007), $182-183$.

53. Ibid., 183.

54. Ibid., 182.

55. Agreement on Cooperation on Aeronautical and Maritime Search and Rescue in the Arctic (signed May 12, 2011, entered into force January 19, 2013); Agreement on Cooperation on Marine Oil Pollution, Preparedness and Response in the Arctic (signed May 15, 2013).

56. PAME, Arctic Offshore Oil and Gas Guidelines.

57. Arctic Council BC and Methane Framework for Action.

58. Koivurova, Kankaanpää, and Stępień, 'Innovative Environmental Protection'.

59. Hønneland and Stokke, International Cooperation and Arctic Governance, 166.

60. Kankaanpää and Young, 'The Effectiveness of the Arctic Council', 1.

61. Stockholm Convention on Persistent Organic Pollutants (signed May 22, 2001, entered into force May 17, 2004) UNTS 119: 2256 (Stockholm Convention). 
62. Minamata Convention on Mercury (signed October 10, 2013).

63. For an overview of the Council's influence in the Minamata Convention negotiations see Koivurova, Kankaanpää, and Stępień, 'Innovative Environmental Protection', 298-300.

64. On the role of the Inuit Circumpolar Council in the negotiation process see Jessica $M$ Shadian, The Politics of Arctic Sovereignty: Oil, Ice, and Inuit Governance (Abingdon/New York: Routledge, 2014), 157-160.

65. The US has signed but not ratified the Convention yet. See Center for International Environmental Law, 'U.S. Ratification of the Stockholm Convention: Analysis of Pending POPs Legislation', 2006, accessed March 29, 2016, http://www.ciel.org/Publications/ POPs_Bills_28Feb2006.pdf.

66. Stockholm Convention preamble.

67. Linda Nowlan, Arctic Legal Regime for Environmental Protection, IUCN Environmental Policy and Law Paper 44 (Gland, Switzerland: IUCN, The World Conservation Union, 2001), 16.

68. Stockholm Convention art 16.

69. Arctic Monitoring and Assessment Programme is a Working Group of the Arctic Council.

70. Arctic Monitoring and Assessment Programme, 'Trends in Stockholm Convention Persistent Organic Pollutants (POPs) in Arctic Air, Human Media and Biota' (Oslo, 2014), 17.

71. Koivurova, Kankaanpää, and Stępień, 'Innovative Environmental Protection', 300.

72. Main short-lived climate forcers are BC, methane, tropospheric ozone and some hydrofluorocarbons.

73. Arctic Council Secretariat, Tromsø Declaration of the 6th Ministerial Meeting of the Arctic Council (April 29, 2009).

74. Arctic Council Task Force on Short-Lived Climate Forcers, 'Progress Report and Recommendation for Ministers', 1.

75. Arctic Council Task Force on Short-Lived Climate Forcers, 'Recommendations to Reduce Black Carbon and Methane Emissions to Slow Arctic Climate Change' (2013);, 'Progress Report and Recommendation for Ministers' (2011).

76. Kiruna Declaration.

77. Ibid.

78. Ibid.

79. Arctic Council BC and Methane Framework for Action.

80. Arctic Council TFABCM, 5th Meeting Summary Report (Iqaluit, September 29-October 1, 2014).

81. Arctic Council, $9^{\text {th }}$ Ministerial Meeting, April 24-25, 2015, accessed March 28, 2016, https://oaarchive.arctic-council.org/bitstream/handle/11374/921/ACMMCA09_Iqaluit_2015_ PRESS_BROCHURE_18_April_2015.pdf?sequence=1.

82. 'Arctic Council Black Carbon Deal a Breakthrough, U.S. Lawyer Says', Nunatsiaq Online, April 24, 2015, accessed March 28, 2016, http://www.nunatsiaqonline.ca/stories/article/ 65674arctic_council_black_carbon_deal_a_breakthrough_u.s_lawyer_says/.

83. Anna Vinogradova, 'Anthropogenic Black Carbon Emissions to the Atmosphere: Surface Distribution through Russian Territory', Atmospheric and Oceanic Optics 27, no. 12 (2014): 1059. [in Russian].

84. Chief Michael Stickman of the Arctic Athabaskan Council quoted in Heather Exner-Pirot, 'Arctic Council Ministerial - Winners and Losers', Alaska Dispatch News, April 29, 2015, accessed March 29, 2016, http://www.rcinet.ca/eye-on-the-arctic/2015/04/27/arctic-councilministerial-winners-and-losers/.

85. Koivurova, Kankaanpää, and Stępień, 'Innovative Environmental Protection', 297; MarcAndré Dubois and Clive Tesar, 'Making It Stick - A New Approach to Implementing 


\section{Shapovalova}

Arctic Council Decisions \& Recommendations', Arctic Yearbook, 2014; US Government Accountability Office, 'Better Direction and Management of Voluntary Recommendations Could Enhance U.S. Arctic Council Participation', May 2014, 41; Kankaanpää and Young, 'The Effectiveness of the Arctic Council', 4-5; Kristine Offerdal, 'Oil, Gas, and the Environment', in International Cooperation and Arctic Governance: Regime Effectiveness and Northern Region Building, ed. Geir Hønneland and Olav Schram Stokke (Abingdon/New York: Routledge, 2007), 141.

86. Arctic Council BC and Methane Framework Annex A.

87. Project description available at $<$ https://oaarchive.arctic-council.org/bitstream/handle/11374/ 389/ACMMCA09_Iqaluit_2015_ACAP_Murmansk_bus_fleet_upgrade.pdf?sequence=1 > accessed 1 June 2016.

88. Arctic Council, Senior Arctic Officials' Report to Ministers (24 April 2015) 14.

89. Ministry of Natural Resources and Environment of the Russian Federation, 'National Report on the Actions on Black Carbon and Methane Emissions', September 2015, 4-5.

90. Daria Shapovalova, 'The Effectiveness of Current Regulatory Models of Gas Flaring in Light of Black Carbon Emissions Reduction in the Arctic', in Global Challenges in the Arctic Region: Sovereignty, Environment and Geopolitical Balance, ed. Elena Conde and Sarah I Sánchez (Abingdon/New York: Routledge, 2017).

91. Ministry of Natural Resources and Environment of the Russian Federation, 'National Report on the Actions on Black Carbon and Methane Emissions', September 2015, 16.

92. Implementation Framework for the National Strategy for the Arctic Region, March 2016, $28-9$.

93. Department of the Interior, Bureau of Ocean Energy Management, 30 CFR Part 550, Air Quality Control, Reporting, and Compliance, Proposed Rule, 19724.

94. Government of Canada, available at $<$ http://ec.gc.ca/pollution/default.asp?lang=En\&n= D9D3F803-1> accessed 14 June 2016.

95. Environment and Climate Change Canada, Canada's Black Carbon Inventory 2016 available at <http://ec.gc.ca/Air/3F796B41-0B87-4C14-B76D-899D23CD0295/Black Carbon 2016-EN-Final.pdf $>$ accessed 14 June 2016.

96. Norwegian Environment Agency, 'Summary of Proposed Action Plan for Norwegian Emissions of Short-Lived Climate Forcers', 2014.

97. Carbon Limits, 'Best Practices for Reduction of Methane and Black Carbon from Arctic Oil and Gas Production', 2012.

98. AMAP, 'AMAP Assessment 2015: Black Carbon and Ozone as Arctic Climate Forcers', 2015, accessed March 28, 2016, https://arcticcouncil.longsight.com/handle/11374/1607.

99. Rachael L Johnstone, 'The Black Carbon and Methane Framework: Balancing Ownership and Effectiveness', Current Developments in Arctic Law 3 (2015).

100. AMAP, Summary for Policy-makers: Arctic Climate Issues 2015, Short-lived Climate Pollutants (2015) 9.

101. AMAP, 'AMAP Assessment 2015', 43-5.

102. The importance of such coordination was stressed prior to adoption of the Arctic Council BC and Methane Framework: Arctic Council Task Force on Short-Lived Climate Forcers, 'Recommendations to Reduce Black Carbon and Methane Emissions to Slow Arctic Climate Change', 14.

103. Arctic Council BC and Methane Framework for Action Annex B.

104. It is also in accordance with art $14 \mathrm{c}$ ) of the UNEP Manual on Compliance with and Enforcement of Multilateral Environmental Agreements (2006).

105. Environment and Climate Change Canada, Canada's Black Carbon Inventory 2016, 4 available at <http://ec.gc.ca/Air/3F796B41-0B87-4C14-B76D-899D23CD0295/Black Carbon 2016-EN-Final.pdf $>$ accessed 14 June 2016. 
106. The implementation of the Offshore Oil and Gas Guidelines was not examined by the Council. The only country we know has implemented the Guidelines is Greenland. Koivurova, Kankaanpää, and Stępień, 'Innovative Environmental Protection', 297. quoting Betsy Baker, 'The Arctic Offshore Oil and Gas Guidelines in Greenland and the Russian Federation', White Paper (Vermont Law School Institute for Energy and the Environment, 2011).

107. See e.g. Norwegian Environmental Agency, 'Summary of Proposed Action Plan for Norwegian Emissions of Shortlived Climate Forcers' (2014); Finland conducted research on evaluation of BC cuts in the country in 2011-2013, accessed March 28, 2016, http:// www.iiasa.ac.at/web/home/research/researchProjects/MACEB.en.html.

108. E.g., Finland voluntary submitted the BC inventory to the CLRTAP in 2014.

109. Hans Corell, 'Reflections on the Possibilities and Limitations of a Binding Legal Regime', E P \& L 37, no. 4 (2007): 321-24; Koivurova, Kankaanpää, and Stępien, 'Innovative Environmental Protection'.

110. In addition to simplified reporting to the Arctic Council, the AMAP holds coordination meetings with the CLRTAP, accessed March 28, 2016, http://www.amap.no/events/ meeting/amap-lrtap-coordination-meeting.

111. Thomas Levander and Svante Bodin, Controlling Emissions from Wood Burning: Legislation and Regulations in Nordic Countries to Control Emissions from Residential Wood Burning An Examination of Past Experience (TemaNord, 2014).

112. Koivurova, Kankaanpää, and Stępień, 'Innovative Environmental Protection'. 